\title{
INESCAPABILITY REVISITED
}

\author{
LUCA FERRERO \\ University of California - Riverside \\ Department of Philosophy \\ Riverside, California \\ U.S.A. \\ luca.ferrero@ucr.edu
}

\begin{abstract}
Article info
CDD: 100

\section{Keywords:}

Constitutivism

Shmagency

Agency

Inescapability
\end{abstract}

Received: 05.08.2018; Accepted: 13.08.2018

DOI: http://dx.doi.org/10.1590/0100-6045.2018.V41N4.LF

\begin{abstract}
According to constitutivism, the objective authority of practical reason is to be grounded in the constitutive features of agency. In this paper, I offer a brief survey of the basic structure of constitutive argument about objectivity and consider how constitutivism might dispel the worry that it can only ground a conditional kind of authority. I then consider David Enoch's original shmagency challenge and the response in terms of the inescapability of agency. In particular, I revisit the appeal to inescapability in light of Enoch's restatement of the challenge in 'Shmagency Revisited'. I argue that the revised challenge still fails but that it helps clarify: first, the distinction between external and internal challenges to constitutivism, and, second, the existence of at least different kinds of inescapability of agency (metaphysical, psychological, and dialectical). I argue that only dialectical inescapability is helpful to show that constitutivism is a viable metanormative theory. I conclude by claiming that an internal challenge to constitutivism is still possible in principle but that the burden of proof has shifted once again to the critics of


constitutivism.

\section{INTRODUCTION}

\subsection{Constitutivism}

In the current philosophical literature on practical reason and metaethics, it has become increasingly common to talk about 'constitutivism.' Roughly speaking, a constitutivist theory purports to establish the objective validity of demands of practical reason on the basis of the nature of agency. By claiming that agency is the ground of objective validity, constitutivism has two immediate attractions: first, it relies on a ground that should be free of substantive (and more controversial) normative assumptions; second, it promises to establish objective validity by eschewing the problematic features of realism; in particular, it avoids claiming that certain demands are objectively valid by 'being part of the fabric of the world' (Williams 1995).

Several philosophers have tried to make good on the promises of constitutivism (for instance, Korsgaard 2009, Velleman 2009, Smith 2013, and Smith 2015) but powerful objections have been raised to the viability of the constitutivist strategy in its most general form (most notably Enoch 2006 and Enoch 2011, but see also Tiffany 2012 and Setiya 2014).

In this paper, I will focus on the most famous objection to the viability of constitutivism-David Enoch's shmagency challenge, and the response offered by constitutivist by appealing to the so-called inescapability of agency. In particular, I will consider whether Enoch (2011)'s reinstatement and refinement of the original challenge succeeds in rebuffing the inescapability defense best articulated by Velleman (2009) and myself (Ferrero 2009). I 
will argue that the shmagency challenge still fails and constitutivism remains a viable strategy. But the revised shmagency challenge helps us get a better understanding of the different ways in which agency has been thought to be inescapable and of the reason why many of them ultimately are of no help to constitutivism. Before doing so, I will offer a brief overview of what constitutivism is supposed to accomplish and of the 'basic constitutive' move, which is the source both of constitutivism's initial appeal and of the skeptical questions that lie behind the shmagency challenge.

\subsection{WHAT CONSTITUTIVISM TRIES TO ACCOMPLISH}

At the core of constitutivism is the appeal to the nature of agency to accomplish two things:

1. the derivation of substantive norms or reasons (usually about morality or practical rationality), and

2. the grounding of the 'objective' authority or validity of these norms or reasons

In its most ambitious form, constitutivism attempts to derive the basic norms of morality (Korsgaard 2009 and Smith 2015). Less ambitious versions stop short of morality but try to establish some constraints on practical norms (Katsafanas 2013) or prepare the ground for a pro-moral development and orientation (Velleman 2009). In addition, the substantive norms might extend beyond the domain of action and intention: the nature of agency might also provide the grounds for norms and reasons about beliefs and desires (Smith 2015). ${ }^{1}$

1 The substantive import of constitutivism might be more indirect than the derivation of norms. From the nature of agency, one might 
Many have argued that the nature of agency provides too thin a ground for any substantive derivation (see Tiffany 2012 and Setiya 2003 but compare Setiya 2014). This is a serious concern, but I won't discuss it in this paper. What I am interested in establishing here is only the preliminary question whether a constitutivist strategy might even get off the ground to secure objectively valid norms or reasons regardless of how substantive these norms or reasons might turn out to be.

\subsection{OBJECTIVITY}

The objective validity of the norms and reasons is a matter of their unconditional authority-of their being valid irrespective of the agent's contingent motives or attitudes. This authority is not necessarily independently of any motive whatsoever but if any specific psychological item is required to ground this authority, such item would have to be a necessary constitutive element of agency as such.

It is also possible for constitutivism to secure a more 'restricted' kind of objectivity. In addition to the maximally objective norms and reasons, which are established independently of any contingent motive, there might be norms and reasons that are valid only on the basis of motives and attitudes that are distinctive of more specific forms of agency, rather than agency as such. These norms would be, in Walden (2012)'s apt terminology,

try to establish some substantive features of reasons for action and of practical justification-substantive in the sense that they offer more than a purely formal and empty characterization of reasons for action. Additional steps might then be required to establish more specific and contentful norms and principles (see Velleman 2009). 
'contingently categorical.' They are categorical because their authority is still independent of particular attitudes or motives of the agents, but they are contingent because their authority depends on specific 'realizations' of agency (to continue using Walden's terminology). Although these realizations are not constitutive of agency, they might still run quite deep and they might be inevitable for agents like us (consider, for instance, the realizations of agency due to the distinctive diachronic structure of our temporally extended agency or the realizations due to our being agents necessarily prone to the lures of temptation).

An account of a more restrictive objective validity would still count as a form of constitutivism as long as it tried to ground this validity in the structure of agency, even if a structure that only pertains to the specific shape that agency must take in order to be realized in our world.

In the limiting case, the objectivity secured by constitutivism might be limited to the basic framework for the derivation of reasons for action, even if these reasons always depend on the contingent features of the agent's motivational set. ${ }^{2}$

In its most general form, a constitutivist account of the authority of norms is supposed to ground objective authority on the basis of the constitutive features of agency. A more restrictive form of constitutivism will do so only in conjunction with some contingent elements of the agent's psychology (and if so, the degree of objectivity will reflect the extent of the contingent elements to which

${ }^{2}$ For instance, it might still be possible to count as constitutivist a theory like Street (2012)'s Humean constructivism, a theory that claims that the moral values are entailed from within the practical standpoint - from within the constitutive features of valuing - but only in conjunction with the contingent set of values of each distinct individual. 
it appeals).

In all of its forms, however, constitutivism is supposed to offer an alternative to a realist account of objective authority. According to constitutivism, this authority is not supposed to be secured by 'the furniture of the world,' i.e., by normative facts that would hold independently of the nature of agents and their practical standpoints. This antirealism is the most direct meta-ethical import of constitutivism. ${ }^{3}$

\section{The Constitutive Move}

\subsection{THE CONDITIONAL CONCLUSION}

At the heart of any constitutivism argument is what might be called the 'basic constitutive move:' the appeal to the constitutive features of agency to ground normativity.

${ }^{3}$ Does constitutivism have additional meta-ethical implications? Many constitutivists have argued against the traditional way of doing meta-ethics (Korsgaard 2003, Velleman 2009) and it is often suggested that constitutivism itself might count as a self-standing meta-ethical view-especially in the guise of 'constructivism' (see Bagnoli 2017). In this paper, I will set this issue aside. This is because whether constitutivism can count as a meta-ethical view in its own right is independent of the fate of its main goal: the grounding of objective normativity on the nature of agency. Constitutivism is not necessarily in trouble even if, as Silverstein (2012) argues, constitutivism needs to be supplemented by a traditional meta-ethical view to deal with traditional meta-ethical problems, especially the challenge raised by error-theory. As Silverstein himself claims, the main constitutivist strategy is still valuable to address questions internal to our practice of making normative judgments, which is all that I am concerned with in this paper. 
How is this move supposed to work? Let's begin by considering how one might appeal to the constitutive features $f$ of a generic item or enterprise $E$ to ground norms that govern that item $E$.

Here is the generic (and trivial) constitutive move: as long as the agent $A$ has a reason to either promote or sustain the existence of $E, A$ has a reason to make sure that the purported $E$ exhibits its constitutive features $f$. This reason is only conditional: its validity is contingent on the fact that $A$ has an independent reason to promote or sustain E. ${ }^{4}$

\subsection{Constitutive Aims}

What happens when we consider the conduct of the entity itself? Let's take an entity capable of self-motion and with a constitutive function of its own. This entity can be said to have not just a constitutive function but a constitutive aim. By its very nature, this entity orients its operation toward the pursuit of this aim, which thereby sets the conditions of success of the entity's characteristic operation.

These conditions do not yet yield any reason for action, not even for the entity itself. To begin with, the entity in question might not even have the capacity to appreciate,

${ }^{4}$ In a similar vein, we can only get conditional conclusions from constitutive features that are-to use Thomson (2008: 19-21)'s expression- 'goodness-fixing' for E. For instance, an entity E that belongs to a functional kind $K$ can be assessed as being (more or less) good to the extent that it meets the functional features that are constitutive of membership in $K$. Judgments about the functional success of $E$ must refer to $E$ 's constitutive features, but this says nothing about whether there is any reason to either value or promote E's existence. For a more extended discussion of the constitutive move, see Ferrero (forthcoming). 
think about, and make explicit the conditions of success of its characteristic operation. If so, these conditions might not work as reasons proper but simply as what Dennett (1984: 24-5) calls 'free-floating rationales.' But even for an entity that has the capacity to act for reasons (and possibly appreciate them as such), it is not clear whether having a constitutive aim necessarily give rise to any reason for the entity to pursue that aim.

One might claim that, at the very least, the entity has a pro tanto reason to pursue its own constitutive aim, just in virtue of having that aim. This would be because an agent always has a pro tanto reason to pursue any aim that she happens to have, even when it is not a constitutive aim. But to make this claim one would have to rely on a substantive normative principle about the relation between aims and reasons. Such a principle could not be made available to the constitutivists in their attempt to ground the categorical authority of the basic norms of practical reason. For this principle would be among those principles whose authority is supposed to be accounted for by constitutivism. This is not to deny that this principle might be grounded on the nature of agency. But even so, it seems that we should not rely on this principle in the very argument that is supposed to establish its validity. ${ }^{5}$

5 A similar worry is raised by Korsgaard (1997) and Velleman (2009) concerning the grounding of the instrumental principle. Notice that here I am not denying that possessing an aim might generate a basic structural normative pressure concerning the combination of the subject's attitudes. If Buss (ms) is correct, there might be a conceptual constraint of self-interpretation that requires that we can self-attribute an aim only if, at the same time, we self-attribute the intention to take the known necessary means to it. But such a principle of self-interpretation, grounded on the conditions for being a unified subject, does not generate practical norms: it does not tell us what to do, and it gives us no 
Does the constitutive nature of the aim make a difference? At first blush, it might seem so. Contingent aims do not by themselves generate reasons to act on them. But if an entity is under a categorical demand to secure its own continued existence, then this entity would be under a categorical demand to continue to be guided by its constitutive aim, given that having this aim is essential to the item's own continued existence. A permanent failure to continue to be guided by the aim would amount to the entity's disappearance.

The prospect of death might be a most powerful threat. The pursuit of a constitutive aim might thus underlie many of the entity's other aims. However, it does not seem that, necessarily, there is an unconditional requirement for any given entity to continue to support its own existence. In our own case, for instance, the question of whether we have reasons to continue to live appears to be a substantive practical question-one whose answer might be contingent on each individual's attitudes. ${ }^{6}$ Although there might often be a powerful substantive pressure for an entity to continue to support its own existence by way of continuing to pursue its constitutive aim, this pressure is not unconditional. Hence, the presence of a constitutive aim, as such, might not be able to provide the foundation of the objective validity of practical reason.

substantive reasons, not even pro tanto reasons, to do anything in particular- even if the aim happens to be a constitutive one.

6 See for instance Williams (1973) discussion of the individual's need to have her own categorical desires-desires that are not conditional on the assumption of our continued existence-to resolve the practicalquestion of whether she is to continue to live. 


\subsection{The SKePtical Challenge}

The previous considerations should make us cautious about the role that constitutive aims might play in grounding the objective validity of practical reason. The appeal to constitutive aims can be powerful when it is used internally: as long as one has an independent reason to promote both the operation and the existence of a given item $E$ (including oneself), one can easily dispel skeptical worries about the authority of the norms that can be derived from the nature of $E$, including its constitutive aim. Failing to abide by these norms just makes it impossible for one to deal with $E$ as an $E$, because of the very nature of $E$.

One cannot get around these constraints. The constitutive features of $E$ are internally inescapable for any agent who is set on engaging with $E$. These features, however, can be externally dispensable. They say nothing about whether one has any reason to engage with $E$ in the first place, including the case where the agent herself happens to be the item in question. This is why the norms generated by the nature of $E$ turn out to have only a conditional authority for whoever is to engage with $E$.

This conditional authority is not sufficient, however, to dispel external skeptical challenges-challenges about the demand to engage with $E$. Why should one engage with $E$ in the first place? One might care about, desire, value, or be committed to the engagement with $E$ but these cares, desires, values, and commitments might, in turn, be normatively contingent. By themselves, these cares, etc. are unable to show that it is necessary for anyone to categorically acquire or retain them. Maybe the engagement with $E$ is made necessary in light of one's commitment to the engagement with some other entity $F$ but then the external skeptical challenge would target one's engagement with $F$. If constitutivism is to succeed, therefore, it has to show 
how to stop the regress of the request for external justification so as to secure the categorical force of the demands that can be derived directly from the constitutive features of $E$.

\subsection{RESTRICTED CONSTITUTIVISM}

Before trying to show how constitutivism about agency might try to stop the external challenge, let me briefly return to 'restricted' constitutivism. Even if constitutivism is ultimately unable to ground objective norms, there might still be much to learn about the practical implications of the nature of agency. Many important substantive norms might have deep roots in the nature of agency, even if these roots do not go as far as securing the objective validity of these norms.

Consider, for instance, what Bratman (2013) calls the 'fecundity of planning agency.' Bratman has recently articulated a theory of human agency that shows how the capacity for planning agency provides the common ground for both shared intentional agency and for temporallyextended and self-governed intentional individual agency. This common ground helps us understand not only the conceptual and metaphysical structure of these capacities but also their normative structure and import. In addition, this understanding allows for the norms of these kinds of agency to be stable under reflection (Bratman 2018).

Bratman is adamant that the authority of the norms derivable from the structure of planning agency is only conditional: it depends on our having a prior reason to be self-governing. Whether we have such a reason and whether this reason hasobjective validity are matters to be established independently of the normative implications of planning agency. Moreover, Bratman does not claim that planning agency is the only kind of agency, even if it might 
happen that, for beings like us, such agency is inescapable.

Is there any lesson that constitutivism can learn from such a theory, even if it does not purport to account for the objective validity of practical reason? A Bratman-style response to the skeptic amounts to the 'raising of the stakes.' Given that the nature of planning agency lays at the roots of the basic substantive norms that govern both individual and social agency, Bratman is able to show that the skeptic can reject the force of these norms only by giving up a very large and unbreakable package —one that includes both planning agency and all other kinds of intentional agency, both individual and shared, that go together with planning.

According to this 'package strategy,' the skeptic cannot ultimately challenge the authority of the norms of planning agency in a piecemeal fashion. If so, only the most radical skeptic is left standing, the one who is willing to give up on any agency that is temporally extended, selfreflective, and shared. But this is an extremely high price to pay. Hence, even if a Bratman-style restricted constitutivism ultimately only argues for the conditional authority of the norms of planning agency, it does so in a way that takes care of most skeptics. For most skeptics would already find themselves to be committed to some portion of the unbreakable package and thus compelled to accept it in its entirety on pain of giving up on it altogether. The strength of the package strategy depends, therefore, on the extent of the unbreakable package: the larger the package, the stronger the strategy.

A Bratman-style strategy does not secure the objective validity of practical reason but it shows how a restrictive constitutivism might have a substantive payoff. By forcing the die-hard skeptic in a position that is so radical and extreme that she is to give up such a large package of requirements and all the associated forms of agency, the concern with the conditional character of this defense 
might be minimized. The regress of the external challenge might be stopped at a place that is shared by most and that comes with far-reaching normative implications, a place that most will find so appealing as to harbor no worry about its residual contingency. ${ }^{7}$

\section{What is So Special About Agency?}

\subsection{AgENCY AND REgRESS}

As attractive as restricted constitutivism might be, we should not yet despair of the possibility to defend a version of constitutivism that grounds categorical norms and reasons. In order to do so, one needs to show how to stop the regress of the external skeptical challenge. The standard constitutivist suggestion is that there is something special about agency that blocks the external question of whether we have reason to engage in the enterprise of agency, i.e., to be agents.

In outline, the suggestion is that agency is necessarily 'inescapable.' If we cannot but be agents, the external question whether we have a reason to be agents cannot be raised. There is something categorical about our status as agents and, a fortiori, about the normative implications of this status. Or so constitutivists often argue.

The appeal to inescapability plays a prominent role in the response to the most famous objection to constitutivism, the shmagency challenge first articulated in Enoch (2006). In this section, I will first briefly outline the original shmagency challenge and the responses offered

7 A similar line of response to the skeptical regress was first articulated by Railton (1997) in a paper that is often read as being more critical of constitutivism than it actually is. 
by Velleman (2009) and myself (Ferrero 2009). I will then discuss Enoch (2011)'s reformulation of the shmagency challenge and how appeal to the various kind of inescapability of agency might or might not help constitutivism.

\subsection{THE ORIginal SHMAgENCY CHALlENGE}

In the original presentation of the shmagency challenge, Enoch (2006) suggested that there could be a subject-the shmagent-who is very similar to an agent but lacks the constitutive aim of agency. To convince such a subject of the categorical authority of the norms of practical reason, it is not sufficient to show that these norms can be derived from the nature of agency. A shmagent should also be given a conclusive reason to be an agent, that is, to acquire and care about the constitutive features of agency. Likewise, given the possibility of shmagents, agents can raise the question whether they themselves have reason to be agents rather than shmagents.

Enoch did not deny that there might be a reason to be an agent and that such reason might be available to the shmagent. But he argued that this reason could not be established by appeal to the constitutive features of agency. This is because such a reason should in principle be made available to shmagents, who don't care about the constitutive features of agency. If this is correct, there is at least one reason-the reason to be an agent-whose categorical normativity cannot be grounded in the constitutive features of agency. This is sufficient to show that constitutivism cannot make true on its promise to account for the categorical authority of practical reason. Or so Enoch (2006) argued. 


\subsection{THE INESCAPABILITY OF REFLECTIVE CLOSURE}

Velleman (2009) and Ferrero (2009) responded, on behalf of constitutivism, by arguing that there is a crucial difference between ordinary enterprises and agency. In the case of an ordinary enterprise $E$, one can always ask the external question whether one should engage in $E$. The question is external since it can be asked from outside of $E$, that is, when one is not engaged in $E$ or one does not care about $E$. No comparable question, however, can be raised about agency itself. For agency is inescapable: there is no place 'outside' of agency whence one could raise the question whether one has reason to be an agent. Hence, there cannot be any shmagent, there cannot be any subject who could raise the external question whether she should acquire and care about the constitutive aims of agency.

The kind of agency that is claimed to be inescapable is intentional or rationalagency, the agency that is exercised when the subject's doings are not mere behavior, but something done for reasons (Velleman 2009). The inescapability is a matter of the reflective closure of the exercise of practical reason. To be a rational agent is, by definition, to be an agent who is responsive to the issuances of practical reason. Any question about whether there is reason to engage in any enterprise can, therefore, only be raised by this kind of agents, that is, by subjects who are exercising their capacity for rational agency. The same is true about the question whether there is reason be such an agent. That is, the enterprise of rational agency is - as I wroteclosed under its own distinctive operation (Ferrero 2009: 309, see also Walden 2012). There is only one possible standpoint that can be occupied when addressing the question whether there is reason to be a rational agent: the standpoint of the rational agentherself.

This is, in outline, the response offered by constitutivism to defuse the external challenge. But this 
response leaves open the intelligibility of an internal challenge. It is still possible for an agent to consider whether she should be an agent while standing inside of agency, i.e., while continuing to have the constitutive aim of rational agency and continuing to be subjected to its constitutive standards.

The internal challenge under the constraints of inescapability might raise a concern for constitutivism. There is a worry that any response to the internal challenge might suffer from some objectionable circularity. This is a serious concern. But both Velleman and Ferrero (2009: 323) argued that no objectionable circularity arises. Avoiding the circularity does not guarantee, however, that constitutivism has a successful answer to the internal challenge.

Constitutivism might still owe a response to the internal question of whether an agent has a compelling reason to be an agent. The shmagency challenge does not show that one cannot appeal to the nature of agency to find a positive response to the internal question. Pace Enoch, therefore, the constitutivist strategy appears a viable one, even if one that might still need to give a positive answer to an internal challenge, if such a challenge arises. Or so I argued by appealing to what I call 'dialectical inescapability': the inescapability of rational agency in the sense of the closure of this agency under the exercise of its distinctive operation.

\section{SHMAGENCY REVISITED}

\subsection{THE Mistake OF THE ADVERSARIAL STANCE?}

The Velleman-Ferrero-style response has been criticized by Enoch (2011) in a restatement of the original shmagency challenge. In particular, Enoch accuses me of being guilty of making the 'mistake of the adversarial stance.' According to 
Enoch (2011: 218-19), I have been trying to prove that

no one can consistently occupy the position of the relevant skeptic: by the very raising of the challenge to the agency-religion, you show yourself to be a devoted follower. And ... this goes some way towards vindicating agency, and with it presumably constitutivism.

According to Enoch, the problem with this line of response is that it 'dramatizes the challenge' by making the skeptic into an 'actual character with a position to defend.' According to the constitutivists, the skeptic is supposed to engage in a 'kind of adversarial duel' but in so doing he defeats himself by trying to occupy a position that cannot in principle be occupied. Against this conclusion, Enoch argues that

the error here is already present in the very first step, the specific dramatization of the dialogue. The skeptic is not-certainly she need not be-an actual character, with a position to defend. The skeptic, rather, is the embodiment of a problem we face, because of our own commitments.

Toillustrate this point, Enoch (2011: 219-20) offers the example of the 'paper-skeptic' - a philosopher who finds the practice of writing papers (rather than books) intellectually corrupting but presents her case in the form of a paper. Maybe the paper-skeptic is in trouble, given that she presents her case in the form of a paper. ButEnoch continues-even if she were in this sense selfdefeating, we as paper writers are still in trouble. If the paper-skeptic's argument works, we still need to address 
the challenge, given that we are committed to paper writing. We cannot dismiss the challenge as being selfdefeating, given that, at least for the time being, we see no problem with writing papers rather than books.

When applied to the theory of normativity, the example of the paper-skeptic is supposed to prove that

showing that the practical-reason skeptic ... has no safe grounds from which to launch his attack is neither here nor there. It does not even begin to vindicate practical reason. ... It is we who have to come up with a theory of normativity that will be adequate (at least) by our own lights. ... Whether or not there is an agent (or a shmagent) who can stably embody this challenge is beside the point. (Enoch 2011: 219)

On behalf of constitutivism, I find that Enoch's accusation of the mistake of the adversarial stance is somewhat disingenuous, especially on account of the rhetoric of his original paper, which makes abundant use of the shmagent as the main dramatis persona. In Enoch (2006), many of the challenges to constitutivism are presented as if issued by the shmagent as an actual character. Sometimes, they are even put in the shmagent's own words. And many readers, at least in my experience, find themselves moved by the challenge by taking the shmagent as a live possibility.

Nevertheless, Enoch (2011) is right that it would be a mistake to take the adversarial stance in trying to respond to the shmagency challenge. But this is so only if the dramatization of the argument and the claim that the shmagent defeats himself were meant to offer a positive vindication of practical reason. But this was not the goal of my original argument about the impossibility of any 
ground from which to launch the shmagency challenge.

\subsection{THE INTERNAL SHMAGENCY CHALLENGE}

The self-defeat of the shmagent is only supposed to show that the external challenge cannot be launched. This leaves entirely open whether constitutivism might still need to address the internal skeptic and possibly fail in trying to respond to it. Nonetheless, showing that the external challenge does not work does require the dramatization. For the external challenge rests on the possibility of imagining a standpoint external to agency where a subject (playing the role of the shmagent) could intelligibly ask the question whether there is reason to be an agent.

Toprove, with Enoch, that the constitutivist strategy is a nonstarter, it is sufficient to show the intelligibility of raising the question about the reason to be an agent from outside of agency. This challenge would work even if one were not ultimately skeptical about the availability of such a reason. The important point is only whether constitutivism has the resources by itself to provide this reason. Constitutivism cannot provide such a reason all by itself if the reason needs to be available from outside of the enterprise of agency. This is all that it takes for the external shmagency challenge to work.

The dramatization of the shmagent in my response to Enoch is only supposed to show that an external shmagent is impossible on account of the self-defeating character of any attempt at occupying a standpoint external to rational agency from which one could intelligibly ask any question about the reasons one might have to do anything, including being a rational agent. These attempts are selfdefeating because of dialectical inescapability-the closure of rational agency under its distinctive operation. 
This is very different from the case of the paper-skeptic presented in Enoch (2011). The paper-skeptic is supposed to have an argument that is available within the practice of writing papers to the effect that that practice is unjustified. That the argument is presented in a paper does not make the argument self-defeating, even if its writer might be so. And the paper writers should indeed take notice of the argument, which might spell internal troubles for them. To this extent, Enoch is correct. But this concession to Enoch does not spell any trouble for constitutivism.

The shmagency challenge presented by Enoch in both papers is not in the form of an argument that shows that agency cannot possibly be vindicated. All that Enoch has shown is that, were it be possible to occupy the external position, constitutivism would lack the resources to address the external shmagency challenge. The external shmagent does not need to have an argument that shows that there is no reason to be an agent. The shmagent does not need to be a skeptic about practical reason. He only needs to be skeptical about constitutivism, i.e., about the ability of constitutivism to show that he has a reason to be an agent. And this skepticism only requires the intelligibility of raising, from outside of agency, the question of whether to be an agent.

When Enoch discusses the analogy with the paperskeptic, he makes it sound as if he is advancing an internal challenge that calls for an internal response; as if he is showing that constitutivism is either internally inconsistent or inconsistent with our pre-theoretical commitments. But as a matter of fact Enoch does not present any argument to prove such inconsistency. If I am correct, therefore, once the external challenge has been proven to be impossible, constitutivism is not thereby necessarily faced by an internal skepticism.

But Enoch might be correct that constitutivism still needs to address the question whether there is reason to be 
an agent before claiming to have vindicated objective practical reason. If so, the original defenses of constitutivism targeted by Enoch might be incomplete. But nothing that Enoch says in his two papers suggests either that these defenses are inconsistent or that they might have serious difficulties addressing the internal question whether to be an agent. Responding to the threat of internal inconsistency by taking the adversarial stance would indeed be a mistake. But this is not what Velleman and I did. To the extent that we took the adversarial stance, we did so legitimately: we only meant to show the selfdefeating character of the external challenge.

At this point in the dialectic, the critics of constitutivism might embrace two distinct strategies: they could try either to revive the external challenge or to claim that constitutivism cannot address the internal challenge. The constitutivist, in turn, could continue to appeal to the inescapability of agency. There are two ways in which inescapability might help constitutivism. First, it could be used defensively to block the external challenge. Second, it could be used more positively to respond to the internal challenge, either by rejecting it as unintelligible or by offering an answer to the question of why one should be an agent. Let's thus turn to a detailed discussion of the alleged inescapability of agency.

\section{KINDS OF INESCAPABILITY}

\subsection{ESCAPABLE AGENCY}

The aspiration of constitutivism is to ground the authority of practical reason in the metaphysics of agency; to ground the force of the should in the 'bind' of the must. Constitutivism promises to ground one kind of necessity in a different but supposedly more fundamental kind of 
necessity.

This is the allure but also the danger of constitutivism. Is the crossing between these modalities acceptable? How can one move from the 'must' of constitution to the 'should' of unconditional authority? And how is the necessity of the inescapability of agency supposed to help?

Tobegin the exploration of the nature and implications of inescapability, let's first make clear two ways in which agency is not inescapable. First, agency is not ontologically inescapable: agency can be lost, either temporarily or permanently. A subject can go in and out of agency. In particular, it is possible to exit agency (temporarily or permanently) as a result of the exercise of agency (as when one takes a sleeping pill, say, or commits suicide).$^{8}$

Second, our own agency is not temporally inescapable. We are not guaranteed to be agents forever (even if only intermittently so). Rather, we have to work in order to continue to secure our own existence, at least in the long run. And this work might be the fundamental work of agency itself. Being an agent is not, at least for us, a guaranteed condition.

\subsection{The Human Plight}

One way to characterize the alleged inescapability of agency is in terms of the metaphysics of the exercise of agency. Korsgaard famously wrote: "acting is our plight,

\footnotetext{
8 This ontological inescapability seems to be what Smith (2015) has in mind when he speaks of the 'grave mistake' of appealing to our being necessarily agents in articulating a defense of constitutivism. Smith is correct that this would be a mistake, but he is wrong about attributing this reading of inescapability to standard versions of constitutivism.
} 
the simple inexorable fact of the human condition" (Korsgaard 2009: 2). Katsafanas (2013: 52-53) concurs: "It is not as if the agent can do something other than performing actions; action is inescapable;" "Action is inescapable: any attempt to avoid acting will itself be an action."

The intuitive thought in support of the idea that acting is our plight is that any attempt at not acting cannot but be an action, a manifestation of our agency (even if one that, when successful, brings the temporary or permanent demise of one's agency). This is a feature of agency that is not specific to intentional or rational agency. Any agent, even of a simpler kind, is always busy acting in the sense that, as long as it is not in dormant state, this agent is exercising its basic two-way agential powers: its power to either make an antagonistic intervention in the natural course of events or to refrain from such intervention. The latter kind of non-interference is as much a manifestation of agential powers as an antagonistic intervention. In addition, if the agent is set on interrupting the exercise of its two-way powers, it can do so, as an agent, only by an exercise of these very same powers. ${ }^{9}$

In this sense, it is true that for any agent the exercise of its own agential powers is metaphysically inescapable: as long as the agent is awake, the agent cannot but be acting in the sense of continuously exercising its agential powers. But this inescapability does not make the

9 In some cases, the powers are exercised via an antagonistic intervention - say, by taking a sleeping pill, or shooting oneself; in other cases, by refraining from intervening in a course of events that is headed toward the interruption of the exercise of these powerssay, letting oneself fall asleep. Falling asleep is not an exercise of an agential power but letting oneself fall asleep-by refraining to interfere with the non-agential process of falling asleep-is. 
(temporary or permanent) agential exit from agency impossible. It is still possible to exit agency as an outcome of the exercise of one's agency. But if so, it is unclear how this inescapability makes agency different from other escapable enterprises, such as the game of chess. As long as the exit from agency is possible, therefore, isn't the question of whether to stay within agency a perfectly legitimate one?

Active exiting from a chess game is not necessarily a move within the game of chess (although declaring that one is abandoning the game might be so). Active exiting from agency is necessarily a move within the 'game' of agency, so to say. But as long as active exiting is possible, couldn't we ask whether there is a reason to exit from it? The metaphysical interpretation of the inescapability of agency, therefore, still leaves open the internal challenge.

A constitutivist might still argue that there is an important difference between exiting ordinary enterprises, such as chess, and exiting agency. Usually, one can exit an ordinary enterprise immediately. One can stop playing chess simply by deciding to do so, and thereby giving up the pursuit of that enterprise hic and nunc (but for the possible ballistic and inertial effects of the interrupted enterprise).

By contrast, it does not seem that one can exit agency as the unmediated and immediate outcome of the exercise of an antagonistic agential power. One cannot exit agency by fiat, simply by deciding to do so. One cannot just switch agency off, so to say. At most, one can let oneself immediately exit agency when one decides not to interfere with the last stage of an already ongoing process of falling out of agency. In this sense, the operation of agency in its antagonistic form might be said to be locally relentless. One cannot snap out of agency by the basic act of deciding to give it up. This local relentlessness is part of the metaphysics of agency (or at least of our own agency) and it shows that there is an aspect under which our agency is indeed 
inescapable. But this is hardly the kind of inescapability that supports constitutivism. The fact that exiting from agency in the agential mode could not be done immediately does not prove that the internal question is either unintelligible or answerable.

\subsection{THE LABOR OF AGENCY}

Let's consider a different interpretation of the plight of acting. As already suggested above, our agency is vulnerable. For us, being an agent is not a guaranteed condition but an achievement. To continue to be an agent takes work. We are thus under an inescapable and continuous demand to secure the persistence of our agency. In doing so we might rely on some inertial continuity and some form of psychological retention that might not have to be actively and directly sustained. ${ }^{10}$ Even so, our agency appears to be under a constant threat of permanent disappearance: keeping ourselves together might thus be the fundamental work of agency. The continuous labor of our agency in sustaining itself might indeed be our 'plight' - "the simple inexorable fact of the human condition" (Korsgaard 2009: 2).

Nonetheless, the fragility of our condition and the inescapability of the threat and of the labor required to fend it off do not support constitutivism. True, because of our plight, in raising the question whether to be agents, we still need, even if only provisionally, to continue to work at supporting our own agency. In this way, our agency is special. For other kinds of enterprises allow for (and possibly require) their suspension while one is considering

10 For a discussion of some the implications of this inertial retention and its relation to rationality, see Ferrero (2014). 
whether one has reason to engage in them. But the inescapability both of the threat to agency and of the labor of agency do not remove the internal question whether to be an agent. If anything, this inescapability makes the question even more pressing.

\subsection{THE INESCAPABILITY OF CONSTITUTION}

Let's consider another possible interpretation of the inescapability of agency: being an agent is being an agent, there is no way around it. Losing any of the constitutive features of agency amounts to no longer being an agent. This is neither surprising nor exclusive to agency. It is trivially true of any enterprise $E$ that the loss of any constitutive feature amounts to the ceasing of that enterprise $E$ until the feature is regained, if ever.

Calling attention to this 'inescapability of constitution' does not help ground the authority of practical reason. At most, it reminds us of what is at stake in the loss of the constitutive features of agency: the loss of agency itself. For us, this might be a major loss, especially when permanent. This is so if the agency under threat is a necessary condition for the kind of individual existence that we care especially about (or even for the only kind of existence that we might conceivably have).

This is different for ordinary enterprises. The loss of their constitutive features amounts to the loss of the enterprises, not of our existence. In the case of agency, instead, the permanent loss of constitutive features amounts to our own disappearance. The threat of death, therefore, raises the stakes associated with the internal challenge. But the 'inescapability of constitution' does not tell us whether we have reason to (continue to) be agents. Whether we have reason to respect the constitutive standards of agency is still conditional on our having 
reason to be agents, that is, on our having reason to put ourselves under the guidance of those standards.

\section{PSYCHOLOGICAL INESCAPABILITY}

\subsection{INESCAPABILITY AND MOOTNESS}

The various versions of metaphysical inescapability that I have just discussed do not appear to help constitutivism. Could psychological inescapability fare better? Let's consider a motive whose operation is so entrenched that one cannot stop it from influencing one's conduct. This motive can be said to be 'psychologically inescapable.' If one has no choice but be moved by an inescapable motive, the question whether one has a reason to be moved by it appears moot. For it seems that there can be no reasons for action in those circumstances in which the agent has no options.

If agency is inescapable in this sense (that is, if the aims or motives constitutive of agency are psychologically inescapable), the question whether to be an agentwhether to have those aims or motives-is moot. And thus the shmagency challenge, even in its internal form, is defused. Or so it has been argued by Katsafanas (2013) and Velleman (2009). ${ }^{11}$

Does psychological inescapability validate practical reason? Enoch argues that it does not. To show this, he introduces the case of the 'Latent and Grudging Patriot.'

I am a latent and grudging patriot. I reject patriotism and nationalism as morally

11 See Velleman (2009)'s discussion of 'natural inescapability.' 
unjustified. I am willing to defend this position in a philosophical or political argument. And yet I find myself moved by the sorts of thing patriots are moved by (say, a flag, the national anthem, the success of a local sports team). In a sense, then, I care about such things. I can ask, and often have asked 'Why should I care about such things?', and I'm rather confident that the answer is that I should not. If someone then tells me: 'But you do care!' what she says will be true. Perhaps it's even true that (in some sense) patriotism of this kind is inescapable for me, that I cannot avoid it (for what it's worth I've tried). But this does not even begin to answer the question of whether I should especially care about, say, how well my country's tennis team does in the Davis Cup, and, if so, why. That the question whether to care is in a sense moot for me - I cannot stop caring - is neither here nor there. (Enoch 2011: 216)

According to Enoch, the question whether the grudging patriot has reason to care about his patriotism is not moot. It is a perfectly intelligible question, in spite of the inescapability of the patriot's motives. Enoch claims that the psychological inescapability of the constitutive aim of agency would have the same structure as the patriot's motive. By analogy, the question whether we have reason to be agents would be perfectly intelligible even if the constitutive aim of agency were psychologically inescapable.

Enoch does not say much more in support of this conclusion, but I agree that there is something troubling with the suggestion that constitutivism would be helped 
by appealing to psychological inescapability. It is undeniable that absolute lack of control (even of an indirect kind) over certain conditions or circumstances makes moot the question whether we have reasons to do anything about the existence of these conditions. There are no practical questions, for instance, over the existence of a law of nature. But it is doubtful whether a psychologically inescapable motives are truly uncontrollable conditions. And if they are not, constitutivism could not appeal to them to show that the internal challenge is moot.

\subsection{RADICAL INTERVENTIONS}

Are psychological motives truly uncontrollable? It seems not. To begin with, no psychological motive is absolutely inescapable. Even the most recalcitrant motives can in principle be eliminated by taking the extreme option-by terminating one's existence or, possibly, by a radical intervention in one's psychology (say, alobotomy). Hence, the practical question about what to do with respect to the allegedly inescapable motives is not really moot. The issue might seem moot only because ordinarily we frame practical questions (including those about how to handle our motives) under the assumption that we are not going to take the most radical interventions, such as terminating our lives.

Nonetheless, a radical intervention is exactly what is at stake when we raise the issue whether we have reason to be agents. Even if the constitutive aims are psychologically entrenched, they are not genuinely inescapable when we contemplate the question whether we should continue to exist. Hence, the latter question is not in principle moot.

Additionally, the option of terminating constitutive motives is not radical on account of their psychological 
inescapability. It is not radical because it is difficult to remove them. Rather it is radical because these motives are 'inescapable by constitution.' It is simply on account of their constitutive role in agency that removing them amounts to a loss of our existence as full-fledged agents. The motives are psychological inescapable only in the sense that they are constitutive of the psychology of agency.

\subsection{WEAK PSYCHOLOGICAL INESCAPABILITY}

Let's now consider motives that are psychologically inescapable in a weaker sense: they are impossible to remove short of ceasing to exist as an agent. This weaker inescapability does not make all practical questions about the operation of these motives moot. Even if the operation itself cannot be altered, its normative significance might be affected by the stance that we take toward these motives.

In particular, whether we endorse or approve of them is likely to make a decisive difference to the attitudes we take not just toward their operation but also to their normative implications. For instance, a teleologically structured motive might, just on account of the teleological structure, set a condition of success and give us a pro tanto reason to pursue this success (see Katsafanas 2013). However, even if the structure is all that it is required to give rise to a pro tanto reason to pursue the motive's object, the force of this reason is sensitive to our approval or endorsement of the motive. A motive that is not approved might carry little if any rational force (in addition, we might still be held accountable or responsible for the operation of motives that we fail to approve).

Compulsive motives, for instance, might be inescapable in their operation. But this does not grant 
their conditions of success a special and positive normative status. We do not take ourselves to have reason to pursue a compulsive aim on account of its compulsive character. What appears to make a difference for the normative status of the motive and its conditions of success is not the inescapability of the motive's operation but, if anything, our attitude of approval or disapproval of this operation. ${ }^{12}$

This is an unsurprising point, which goes back to the familiar discussion of the differences between the willing and unwilling addict in Frankfurt (1971). This point has important implications for the viability of constitutivism. If the constitutive motives of agency are psychologically inescapable in the mode of a compulsive motive, why should we grant them any special status as fundamental grounds of practical reason?

There are two worries. First, could something with the same psychological character of a 'compulsion' or an 'urge' play this grounding role? If we can be alienated from inescapable motives, it is hard to see how they could provide the grounds for the basic norms of practical reason. The alienation appears to block the authority of whatever norms might be derived from the structure of these motives, including the motives' teleological orientation. It is deeply unsatisfying to suggest that the grounds of practical reason rest in nothing other than our being necessarily 'stuck' with the inescapable operation of psychological forces with which we cannot identify. Could

12 Katsafanas (2013) is aware of this problem as it applies to the inescapability of the will to power (which, according to him, is one of the two constitutive aims of action). Katsafanas (2013: 204-8)'s solution is that we cannot but approve of the operation of this motive. For some reservations about this solution, see Ferrero (2015). 
the source of normativity rest on our being unwillingly addicted to the operation of the constitutive aims of agency?

Second, even if compulsive motives could be the source of normativity, this role would not rest solely (if at all) on their psychological inescapability. By itself, psychological inescapability would not be normatively significant: approval or identification with this inescapable operation would be required. But if so, what is the normative status of this approval? Couldn't we ask whether we have reason for the approval in the first place? Could the answer come from the constitutive features of agency alone? Or is the question about the reason for approval moot? Could the brute fact of our approving be sufficient? In other words, the very questions that were raised about the normative significance of the constitutive and inescapable aims of agency could now be raised about the subject's own stance toward the operation of these aims. But how is constitutivism to address these questions, given that it can no longer appeal to psychological inescapability? Doesn't this raise a new challenge to constitutivism?

\subsection{SEMI-EXTERNAL SHMAGENCY}

The alienation from the operation of constitutive aims raises the possibility of a different kind of shmagency challenge. What could constitutivism say to address a subject who is alienated from her own inescapable agency? To raise this version of the challenge, Enoch (2011) resorts once again to the case of the grudging patriot.

Enoch (2006) already suggested the possibility of this alienated form of agency as an instance of the external standpoint whence to launch the shmagency challenge. The alienation was modeled on familiar scenarios where an 
agent is just pretending to engage in a particular enterprise: for instance, an agent might just be 'going through the motions' of playing chess while being utterly indifferent to the game (for instance, because she is under a threat to conform with the rules of the game).

In response, I argued that an alienated participation of this sort poses no threat to constitutivism (Ferrero 2009: 312). Although the participation is alienated from the constitutive aims of the particular enterprise $E$, the participation in the form of play-acting, simulating, or pretending is still an instance of full-fledged agency, even if one that is directed at different aims than those of the enterprise $E$ (aims that are usually parasitic in conception on those of the alienated enterprise $E$ ).

My argument relied on a distinctive feature of agency, the largest size of 'its jurisdiction:' all enterprises fall within intentional agency in the sense that the intentional engagement in any enterprise necessarily (and unsurprisingly) counts also as a particular engagement in the enterprise of agency (Ferrero 2009: 308). But it is not immediately clear whether a similar response could be issued to the new version of shmagency-as-alienatedparticipation.

What is different in the present form of the challenge is that the alienation is not a matter of an active and nonalienated participation in an enterprise with a distinct aim, as when one is just pretending to be a patriot. The alienation of the grudging patriot appears to go deeper: the subject fails to identify with aims whose operation he cannot stop. There is a difference between a 'pretend' patriot and a grudging and compulsive one.

In the latter case, the grudging patriot's compulsive conduct might not qualify as an intentional activity at all. Hence, one cannot respond to this scenario by insisting that the subject is still falling under the jurisdiction of rational agency (with respect to his patriotic conduct). But 
at the same time, this might create a problem for the shmagency challenge modeled on the grudging and compulsive patriot. What are we to make of the notion of a grudging and compulsive agent? That is, of a subject who is inescapably and compulsively moved by the constitutive aims of agency but fails to identify with them? Can we really make sense of this alienated agent?

\subsection{AlIENATED AGENCY?}

I do not see any problem with admitting the existence of agents who are somewhat reluctant and half-hearted about their condition as agents. They might harbor some doubts and concerns about their status as agents, which might ultimately affect their response to the continuous demands of the labor of agency. They might ultimately let their capacity for agency degenerate or simply take their own lives. It is also possible to be only provisionally committed to agency, as it happens when one calls one's care for agency into question. These kinds of reluctant or provisional commitment to agency are not problematic for constitutivism. The subjects who have these commitments are still agents and, as such, they are still under the authority of the distinctive standards and normative pressures of agency.

The challenge to constitutivism requires a much stronger form of alienation from the constitutive aims and standards of agency. The challenge requires that these aims and standards operate in a compulsive mode. I can only imagine two ways in which a subject might be deeply alienated from her own agency in this mode.

First, consider subjects who are alienated from their agency by being passive observers in a purely receptive way of the operation of their agential capacities. They are like Strawson (1994)'s weather watchers although their passive 
observation is now directed at the psychological operation of their own motives and the resultant behaviors. This observation is utterly detached and external, hence the 'alienation' from their agency. These psychology-andbehavior watchers are utterly passive subjects. The agency that they externally observe is 'their own' only in the sense that they happen to be individually attached to the psychology and the body to which they have a privileged observational access. But the access is still in a thirdpersonal mode: they are not really the agents that they observe. No surprise, therefore, that they are 'alienated' from it. In addition, this alienation is not even a matter of their own choice: they do not have the active powers to either identify with or distance themselves from the operations of the psychology they are observing.

Assuming that we can make sense of these psychology watchers, I do not see how their possible existence might pose a challenge to constitutivism. Although these psychology watchers are indeed outside of agency, the external place that they occupy is not one that could raise skeptical challenges to the authority of practical reason. Nor is practical reason in the business of trying to give the psychology watchers any reason to try to become agents. For constitutivism, psychology watchers are unproblematic shmagents.

The second way in which we might imagine subjects who are alienated from their own agency is a kind of schizophrenia. Imagine subjects who have the agential powers to distance themselves from the compulsive operation of their own motives. These subjects would experience the inner workings of their psychology in the form of series of alienated mental episodes which operate independently of their deep self but such that, in their own functioning are still attempting to abide by the constitutive 
standards of rational agency. ${ }^{13}$ In spite of this profound and massive alienation, for these subjects, there must still be a core psychological functioning that is guided in a non-alienated way by the constitutive aims of agency. This is the operation of their capacity for identification, although one that is exercised to systematically refuse the identification with their own psychological operations. In this scenario, the active self might have shrunk to a tiny speckle (the mere negative exercise of the capacity for identification). But this much agency is still operating in a non-alienated way. If so, no matter how pathological the lack of identification might turn out to be, this schizophrenic subject can at least in principle entertain internal questions about the justification of the operation of one's own psychology, something that is impossible for the fully passive (and unconcerned) psychology watchers.

In other words, no matter how extensive this alienation might be, it is still only alienation from particular exercises of agency rather than from the constitutive aim or standards of agency tout court. These aims or standards still operate in a non-alienated form in the exercises of the subject's spontaneity, the spontaneity that allows one both to distance oneself from exercises of one's agential capacities and to entertain questions about the justification of their operations. To the extent that the subject retains this much identification, one is not really outside of the enterprise of agency. The scope of the object of one's agency might be severely restricted, but it is not eliminated altogether. This much identification (or better, this much lack of self-alienation) appears necessary in order to be a subject for whom the question of whether

13 A possible model for this alienated agency would be the schizophrenia as 'disturbed ipseity' discussed by Louis Sass (1998). 
to be an agent is even intelligible. ${ }^{14}$

This minimal core of rational agency is all that constitutivism requires to reject the shmagency challenge in the guise of 'alienated and compulsive' participation. To be clear, what the constitutivist can legitimately reject is the attempt to show that there is still room for a sort of external challenge, or better a semi-external one, which is supposed to find a standpoint in the interstice between non-alienated agency and the alienated operation of agential capacities.

To sum up, the basic structure of my response to the semi-external shmagency challenge is analogous to the one I offered in Ferrero (2009) against the original version of the challenge: there is no possible external standpoint. The psychology watchers are utterly passive subjects for which the issue of raising questions about reasons cannot arise at all. The schizophrenic subject occupies a standpoint internal to agency, even if one from which the subject keeps failing to identify with the operations of her own psychology.

Before proceeding, let me dispel two possible misunderstandings about the discussion of alienated agency. First, although my argument suggests that there is something self-defeating in the attempt to characterize the semi-external shmagent, I am not guilty of the mistake of the adversarial stance. As in the discussion of the original form of shmagency, the possibility of conceiving of a nonself-defeating standpoint is necessary in order to make sense of the semi-external challenge. Second, defusing the semi-external challenge still leaves open the possibility of a fully internal challenge. The agent's necessary identification with the constitutive aims of agency does not

14 For a related discussion of the connection between the impossibility of self-alienation and agency, see Buss (2013). 
prove that there is reason to be an agent, nor that this reason can be offered by relying exclusively on the resources offered by constitutivism. ${ }^{15}$

\section{CONCLUSION}

\subsection{TACKING STOCK}

Enoch (2006)'s original shmagency challenge had the important merit of forcing the constitutivists out of their complacency about the force of the basic constitutivist move. More work was required to understand the way in which agency might be different from other enterprises and, thereby, be able to support more than a mere conditional authority for practical reason. The most convincing response to the original shmagency challenge, elaborated by Velleman and me, appealed to the dialectical

15 The possibility of massive alienation from the operation of one's agential powers might raise a serious concern about the price that constitutivism might have to pay to address the shmagency challenge. The problem, as it has been forcefully shown by Tiffany (2012), is that in order to succeed in rejecting the shmagency challenge, constitutivism might be forced to rely on a minimal conception of agency, maybe something as minimal as the agency afforded by the semi-alienated agent. Yet such a minimal conception of agency might not have enough resources to accomplish the constructive part of constitutivism, that is, the derivation of substantive practical norms and pressures (for a related concern, see Setiya 2014). This is a very serious concern, and one for which-I must confess-I have no ready answer. But for present purposes it is important to notice that this is a distinct challenge to constitutivism, one that needs to be discussed on a separate occasion. 
inescapability of rational agency in order to show that there is no standpoint from which to launch an external challenge. Dialectical inescapability does not defeat the shmagent as the external skeptic-no argument is presented to prove to the skeptic that he has reason to be an agent. Rather, the external shmagency challenge is defused by showing that it cannot be properly framed while standing outside of agency. ${ }^{16}$

In this paper, I have first argued that Enoch (2011)'s restatement of the shmagency challenge fails in its criticism of Velleman and me. But it helps make clearer, first, that there is an important distinction between external and internal challenges to constitutivism and, second, that defusing the external challenge might still leave constitutivism liable to the internal one. Indeed, Enoch offers some suggestions of how the internal challenge might take shape (namely, by relying either on internal inconsistencies or the alleged possibility of alienated agency). But I have argued that none of them is convincing. Nonetheless, his discussion helps us gain a better understanding of the different ways in which agency might be thought to be inescapable and why many of them do not help the cause of constitutivism. Although Enoch himself often fails explicitly to distinguish between the different kinds of inescapability, his skepticism about the normative import of the appeal to inescapability should have a beneficial effect on the debate. For it forces the constitutivists to be clearer about the kinds of

${ }^{16}$ Notice that defusing the challenge is not the same as claiming — as Katsafanas does - that it is moot because there are no open practical options. A challenge is defused by the absence of the standpoint from which to raise it, whereas a challenge is made moot by the absence of alternative options in trying to address it. 
inescapability enjoyed by agency and the ways that these forms of inescapability are supposed to support constitutivism.

If my analysis is correct, only dialectical inescapability helps the constitutivist cause. At the end of the day, the reconsideration of the role of 'inescapability' undertaken in this paper does not really improve on the original response offered by Velleman and me. It actually raises a new potential issue for constitutivism: what to make of the possibility of an internal challenge in the form of the agent (rather than the shmagent)'s question whether to be an agent. Can dialectical inescapability help with this challenge as well?

\subsection{DIALECTICAL INESCAPABILITY AND THE INTERNAL QUESTION}

In closing, I will offer a brief sketch of how dialectical inescapability might help with handling the agent's internally raised question where to be an agent. It is tempting to think that, in the absence of the external standpoint, not only the external but also the internal question become unintelligible. Or it might be tempting to think that inescapability cannot in principle give any reason to be an agent. ${ }^{17}$

But it seems to me that the internal question is both intelligible and legitimate. What is no longer clear is only whether raising the question counts as a challenge to constitutivism. In the absence of the external standpoint, the significance of the question has changed. When an external standpoint is available, asking about the reason to engage with an enterprise is to ask about the normative

${ }^{17}$ See Walden (2012: footnote 4). 
significance of that engagement in terms that are independent of the constitutive features and standards of that enterprise. The question is whether one is to submit to those standards in the first place. Insisting on the fact that those standards are constitutive of the enterprise does not help with addressing the question whether to submit to them, it just tells the agent what she would be submitting to if she were to engage with that enterprise.

Dialectical inescapability does not remove the significance of the question whether an agent has reason to submit to the standards of agency, given that she has the option of pulling herself out of them: agency is not ontologically inescapable. But because of dialectical inescapability, the agent has no access to independent norms and standards in trying to address the very question whether one is to (continue) to submit oneself to the authority of the norms of agency. Because of this, the fact that the agent can raise the internal question does not count as such as a challenge to the authority of those norms. The internal question is a perfectly intelligible one once it is properly understood within the constraints imposed by the dialectical inescapability of rational agency. ${ }^{18}$

The internal question might turn into a challenge if, in trying to answer it, one were to encounter some internal inconsistencies. If so, the norms of agency would turn out to be seriously unstable under reflection. But the mere logical or conceptual possibility of such inconsistencies does not undermine the authority of the constitutive norms and standards of agency. The burden of proof is on the anti-constitutivist to point out to an actual inconsistency.

It might also be possible in principle for the norms and

${ }^{18}$ For additional discussion, see Ferrero (forthcoming). 
standards of rational agency to fail to be 'reinforced' under reflection, without necessarily becoming unstable as a result. For instance, these norms might turn out never to issue any injunction against the option of exiting from agency. But this would not necessarily undermine the objective authority of these norms, even when they issue a blanket permission to anyone to take oneself out of their jurisdiction. Except that, because of dialectical inescapability, one can exit from their jurisdiction only by permanently exiting from rational agency-thereby dropping out of the jurisdiction of any system of norms altogether.

This is not to suggest that dialectical inescapability protects the authority of agency from any internal challenge. But once external skepticism has been defused, the burden has shifted to the critics of constitutivism to present substantive internal challenges to the authority of the norms of agency rather than simply raise the specter of their possibility. ${ }^{19}$

19 I want to thank the audiences of the various venues where previous versions of this paper were presented, including University of Chicago Practical Philosophy workshop, Marquette University, a meeting of the Action Network at the University of Leipzig, University of Puget Sound, Dartmouth College, and the University of Campinas. Special thanks for comments and criticisms to Carla Bagnoli, Jason Bridges, Agnes Callard, David Enoch, David Horst, Kathryn Lindeman, Lije Millgram, Ariela Tubert, and Kenny Walden. 


\section{REFERENCES}

BAgNOLI, C. (2017). Constructivism in Metaethics, The Stanford Encyclopedia of Philosophy (Winter 2017 Edition), Edward N. Zalta (ed.), URL = https://plato.stanford.edu/archives/win2017/ entries/constructivism-metaethics/

Bratman, M. Planning, Time, and Self-Governance. Oxford University Press, 2018.

The Fecundity of Planning Agency. Oxford Studies in Agency and Responsibility, 1, 47-69, 2013.

Buss, S. The Possibility of Action as the Impossibility of Certain Forms of Self-Alienation. Oxford Studies in Agency and Responsibility, 1, 12-46, 2013.

(ms). Norms of Rationality and the Superficial Unity of the Mind

DennetT, D. Elbow Room. MIT Press, 1984.

ENOCH, D. Agency, Shmagency: Why Normativity Won't Come from What Is Constitutive of Action. The Philosophical Review, 115, 169-198, 2006.

Shmagency Revisited. In M. Brady (eds) New Waves in Metaethics. Palgrave Macmillan, London, 208-233, 2011.

FERrero, L. Constitutivism and the Inescapability of Agency. Oxford Studies in Metaethics, 4, 303-333, 2009.

Diachronic Structural Rationality. Inquiry, 57(3), 311-336, 2014.

Review of P. Katsafanas, Constitutivism and the 
Foundations of Ethics. Ethics, 125(3), 883-8, 2015.

(forthcoming). The Many Faces of Constitutivism. In M. Haase and E. Mayr (eds.). Special Issue on Constitutivism. Philosophical Explorations.

FrANKFURT, H.F. (1971). Freedom of the Will and The Concept of a Person. In The Importance of What We Care About: Philosophical Essays. Cambridge University Press, 1988.

Katsafanas, P. Agency and the Foundations of Ethics. Oxford University Press, 2013.

KorsgaARD, C. The Normativity of Instrumental Reason. In G. Cullity \& B. Gaut, Ethics and Practical Reason. Clarendon Press, 215-254, 1997.

Realism and Constructivism in Twentieth-Century Moral Philosophy. Journal of Philosophical Research, 99-122, 2003.

Self-Constitution: Agency, Identity, and Integrity. Oxford University Press, 2009.

Railton, P. On the Hypothetical and Non-Hypothetical in Reasoning about Belief and Action. In G. Cullity \& B. Gaut, Ethics and Practical Reason. Clarendon Press, 53-79, 1997.

SASS, L. A. Schizophrenia, self-consciousness, and the modern mind. Journal of Consciousness Studies, 543-565, 1998.

SETIYA, K. Explaining Action. Philosophical Review, 112, 339-393, 2003. Intention, Plans, and Ethical Rationalism. In M. Vargas \& G. Yaffe (Eds.), Rational and Social Agency: The Philosophy of Michael Bratman. 
Oxford UniversityPress, 2014.

SILVERSTEIN, M. Inescapability and Normativity. Journal of Ethics and Social Philosophy, 6(3), 1-26, 2012.

The Shmagency Question. Philosophical Studies, 116, 2014.

Smith, M. A Constitutivist Theory of Reasons: Its Promise and Parts. LEAP, 1, 9-30, 2013.

The Magic of Constitutivism. American Philosophical Quarterly, 52(2), 187-200, 2015.

STRAWSON, G. The Weather Watchers. In Mental Reality. MITPress, 1994.

STREET, S. Coming to Terms with Contingency: Humean Constructivism about Practical Reason. In Y. Shemmer \& J. Lenman, Constructivism in Practical Philosophy. Oxford: Oxford University Press, 2012.

Thomson, J. J. Normativity. Open Court Publishing Company, 2008.

Tiffany, E. Why Be an Agent? Australasian Journal of Philosophy, 90(2), 223-233, 2012.

Velleman, J. D. (1996). The Possibility of Practical Reason. Ethics, 106(4), 694-726, 1996.

How We Get Along. Cambridge University Press, 2009.

WALDEN, K. Laws of Nature, Laws of Freedom, and the Social Construction of Normativity. Oxford Studies in Metaethics, 37-79, 2012.

Williams, B. The Makropulos Case: Reflections on the Tedium of Immortality. In Problems of the Self. Cambridge University Press, 82-100, 1973. 
Ethics and the Fabric of the World. In Making Sense of Humanity. Cambridge University Press, 1995.

(cc) $\mathrm{BY}$ 